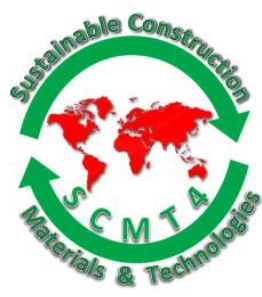

SCMT4

Las Vegas, USA, August 7-11, 2016

\title{
A Study of Properties of Ion-Exchange Resin Mixed Grout: Chloride Diffusion, Strength and Rheology
}

\author{
O. Sanada ${ }^{1}$, H. Mutsuyoshi ${ }^{2 a}$, A. Sumida ${ }^{3}$ and Y. Luan ${ }^{2 b}$ \\ ${ }^{1}$ Central Nippon Expressway Company Limited Tokyo Branch; 4-3-1 Toranomon, Minato-ku, Tokyo 105- \\ 6011 Japan. ${ }^{1}$ Email: <o.sanada.aa@c-nexco.co.jp>. \\ ${ }^{2}$ Saitama University; 255 Shimookubo, Sakura-ku, Saitama-shi, Saitama, 338-8570, Japan. \\ ${ }^{2 a}$ Email: <mutuyosi@mail.saitama-u.ac.jp>, ${ }^{2 b}$ Email: <luanyao@mail.saitama-u.ac.jp>. \\ ${ }^{3}$ Monjyu Technical and Medical Laboratories;3-20-10 Shimouma, Setagaya-ku, Tokyo, 154-0002, Japan., \\ ${ }^{3}$ Email: <monjyu@a07.itscom.net>.
}

\begin{abstract}
In Japan, a number of existing prestressed concrete bridges are suffering chloride attack. Especially in the cases that bridges were constructed decades ago, grouts tending to bleed or swell were often used, and the grouting was not well done. As a result, ducts were not completely filled and voids remained. For the incompletely grouted zones, tendons were vulnerable and more severely corroded. To repair those bridges, effective and economic regrouting materials and method are requisite. Recently, a new repair grout has been developed in the authors' group by mixing ion-exchange resin, a widely used polymer in water purification, into cement paste. Since IER can absorb chloride ions, IER mixed grout is promising to remove free chloride ions in the unfilled duct. In this study, the chloride ion diffusion properties of IER mixed grout was investigated experimentally. Tendons, which were preliminarily spread at the surface with chloride, were grouted using the IER mixed grout. After curing, the chloride amount in the grout was analyzed using potentiometric titration against silver nitrate. It was confirmed that IER effectively absorbed chloride ions from the surface of tendon, and thus is promising to alleviate the corrosion. Furthermore, to promote the practical use, other properties of the grout, such as strength, flowability and bleeding ratio, were tested. It is found that as IER ratio increased strength and flowability tended to decrease but bleeding did not occur. When mix proportion and addition ratio of IER were adopted properly, those properties satisfied the acceptance criterias in design code.
\end{abstract}

\section{INTRODUCTION}

In recent years, a number of prestressed concrete (PC) bridges in Japan which have been serving for decades are suffering chloride attack and corrosion, especially those in harsh environments such as near coast or in heavy snow areas where de-icing agents are used to remove snow in winter. In particular, for some old bridges, ducts containing prestressing tendons were not well grouted when constructed decades ago. Those tendons, without the protection of grout, are more severely corroded due to the ingress of 
chloride contained water. Regrouting and filling up those ducts is necessary, but that is not enough. Despite regrouting, chloride remains at the surface of the tendons, so probably corrosion continues. An ideal way is to remove or alleviate the chloride when doing regrouting. An example is regrouting using grout mixed with lithium nitrite. Passive layer can be reproduced at the surface of tendon. However, nitrite is deleterious to the health of human beings, regrouting material with more safety is requisite. In this study, the authors attempted to mix ion-exchange resin (abbreviated as IER) into grout, and use the grout in the regrouting. IERs are insoluble polymers and capable of trapping particular ions in solution and releasing other ions concomitantly. This ability or process is called ion exchange. IERs are widely used in the water purification and desalination processes of electrical, chemical and food industries. Some type of IERs can trap chloride ions, so grout mixed with such IERs has a potential of absorbing and removing free chloride ions near the ungrouted tendons and alleviating their corrosion (figure 1). In addition, IERs are completely friendly to environment and human beings. In this study, the authors used a strong type anion IER. It has the following ion-exchange process as

$$
\mathrm{R}-\mathrm{CH}_{2} \mathrm{~N}\left(\mathrm{CH}_{3}\right) \mathrm{OH}+\mathrm{Cl}^{-} \equiv \mathrm{R}-\mathrm{CH}_{2} \mathrm{~N}\left(\mathrm{CH}_{3}\right) \mathrm{Cl}+\mathrm{OH}^{-}
$$

Accordingly, chloride ions in pore solution of grout can be exchanged, decreasing the amount of free chloride ions. The $\mathrm{OH}$ - released is beneficial to sustain the alkaline environment. In the past research, the authors mixed the IERs into cement mortar as a repair material for chloride attacked concrete. The chloride ion removing capability of such mortars was experimentally confirmed. In this paper, mixing the IERs in grout, the authors carried out experiment to investigate its capacity of absorbing chloride ions from the surface of tendon. Furthermore, for practical use, the properties of the grout must satisfy the acceptance criterias of strength, flowability and bleeding. Those properties were also experimentally studied.

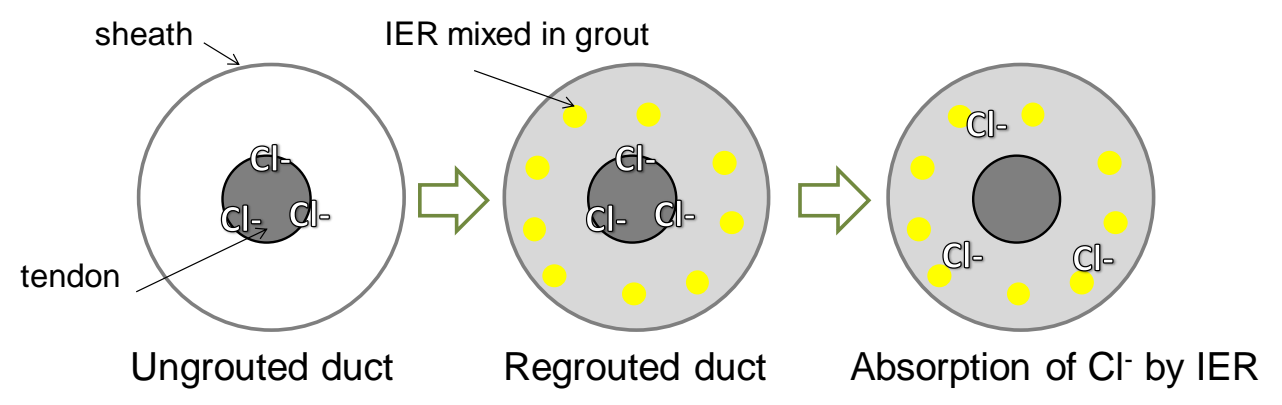

Figure 1. Regrouting of duct using IER mixed grout

\section{CHLORIDE ION ABSORPTION AND QUANTITATIVE ANALYSIS}

\section{Materials and mix proportions}

Ordinary Portland cement, water and IERs were mixed to make grout. Water was distilled before mixing in order to avoid any induced chloride ions. The physical properties of IER are shown in Table 1. Usually those IERs are in the form of granules. In this experiment, to ensure the workability with cement, IER granules were crushed and grinded into powders, and sieved through fines mesh of $300 \mu \mathrm{m}$ to obtain fine ones (figure 2). The mix proportions are shown in Table 2. Water-to-cement (w/c) ratio was constant as $45 \%$. Three addition ratios of IER were prepared, i.e. $0 \%, 3 \%$ and $5 \%$ as the volume of grout, respectively. 
Table 1. The physical properties of the ion-exchange resin

\begin{tabular}{|l|l|}
\hline Molecular structure & Styrene series \\
\hline Type & strong type anionic \& gel form \\
\hline Functional group & $-\mathrm{N} \equiv\left(\mathrm{CH}_{3}\right) 3 \mathrm{X}$ \\
\hline Apparent density $(\mathrm{g} / \mathrm{L})$ & About 660 \\
\hline Moisture retention capacity $(\%)$ & $49 \sim 55$ \\
\hline Effective pH range & $0 \sim 14$ \\
\hline
\end{tabular}

Table 2. Mix proportions $\left(\mathrm{kg} / \mathrm{m}^{3}\right)$

\begin{tabular}{|c|c|c|c|c|}
\hline $\begin{array}{c}\text { IER ratio (by volume } \\
\text { of grout) }\end{array}$ & water & cement & IER & w/c ratio \\
\hline $0 \%$ & 587 & 1,305 & 0 & \multirow{2}{*}{$45 \%$} \\
\hline $3 \%$ & 570 & 1,266 & 35 & \\
\hline $5 \%$ & 558 & 1,239 & 58 & \\
\hline
\end{tabular}

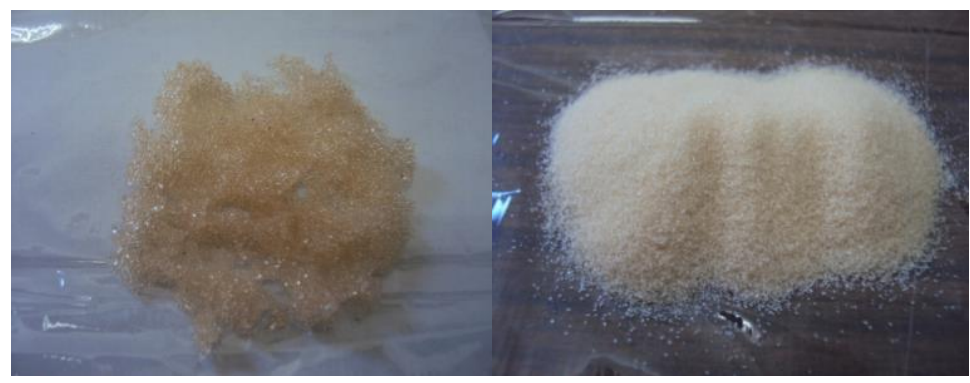

(1) Original granuales of IERs

(2) Grinded and seived powders of IERs

Figure 2. Ion-exchange resin (IER) used in the experiment

\section{Experiment program}

Experiment that simulates a duct containing prestressed tendon and the grouting process was carried out. Figure 3 shows the imitated specimens. A duct with $30 \mathrm{~mm}$ diameter and $100 \mathrm{~mm}$ length was made using polypropylene sheet as the sheath. Two types of steel bar were positioned in the center to imitate a tendon. One was a single deformed bar with $10 \mathrm{~mm}$ diameter. The other was a bundle of three round bars each with $6 \mathrm{~mm}$ diameter. Wood plates with drilled holes were used to fix the duct in two sides. Before grouting, the imitated tendon was preliminarily smeared and spread with sodium chloride at its surface. Shown in Table 3, four types of $\mathrm{NaCl}$ were smeared and spread. For the solution with a concentration of $10 \%$ and $25 \%$ (B1 and B2), they were spread evenly at the surface using gauze pads. The amount of spread $\mathrm{NaCl}$ was calculated by multiplying the weight difference before and after the spreading with the concentration. For the case of $\mathrm{C} 1$, saturated solution was spread, and dried in hot wind. $\mathrm{NaCl}$ solid remained at the surface. For the case of $\mathrm{C} 2$, solid $\mathrm{NaCl}$ particles were directly attached at the surface using water-soluble glue. Fixing the tendon and duct in one side with the wood plate, grouting was carried out, using the three mix proportions in Table 2, respectively. Then, the duct was fixed in the other side. Putty was blocked in the sides to avoid leakage. The specimens were placed at a $20{ }^{\circ} \mathrm{C}$. After one day the wood plates were removed. Then, the ducts containing tendon and harden grout were kept in a sealed container until the age of 28 day and 56 day. 


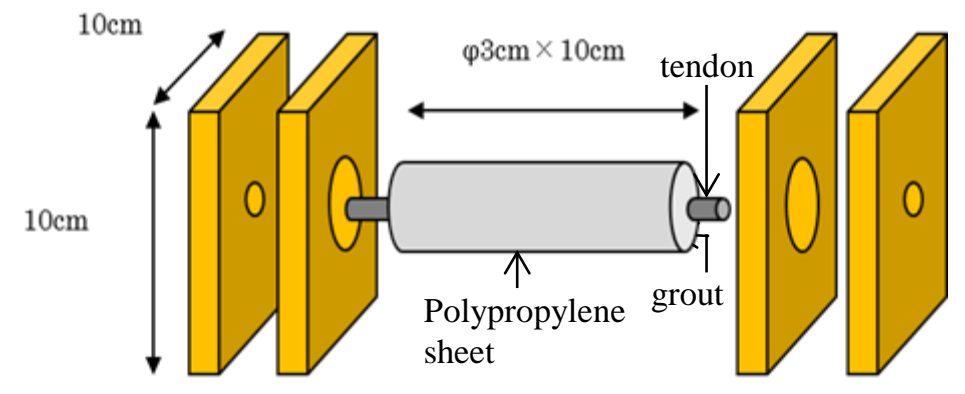

Figure 3. Duct specimens with grout and tendon

Table 3. The type of specimens

\begin{tabular}{|l|l|l|l|l|}
\hline No. & NaCl solution or solid & Tendon & Spreading method & $\mathrm{NaCl}$ amount $(\mathrm{g})$ \\
\hline B1 & $10 \%$ solution & Deformed bar & Spread with gauze & 0.013 \\
\hline B2 & $25 \%$ solution & Deformed bar & Spread with gauze & 0.53 \\
\hline C1 & Saturated solution & Deformed bar & $\begin{array}{l}\text { Spread with gauze and } \\
\text { dried by hot wind }\end{array}$ & 0.15 \\
\hline C2 & NaCl solid particles & $\begin{array}{l}\text { Bundle of three } \\
\text { round bars }\end{array}$ & $\begin{array}{l}\text { Attached using water- } \\
\text { soluble glue }\end{array}$ & 0.80 \\
\hline
\end{tabular}

Before the analysis of chloride amount, first of all, the ducts were taken out from the container. The sheath was removed. The hardened grout was separated from the tendon using hammer. The internal surface of the grout contacting the tendon was carefully cleaned using acetone, to remove any physically adhered chloride particles. Using steel mortar and pestle, grout fragments were crushed into particles, and grinded into powders using a steel mill. The powder was sieved through $149 \mu \mathrm{m}$ mesh. The sieved fine powder was vacuum dried. Subsequently, the amount of chloride ions in the powder was quantitatively analyzed following JIS (Japanese Industrial Standards) A1154:2012 "Methods for test of chloride ion content in hardened concrete". Samples were taken from the sieved powder, and mixed with nitrate acid of $1.0 \mathrm{~mol} / \mathrm{L}$ in a beaker. The suspension was fully stirred, and $\mathrm{pH}$ was assured blew 3.0. Then, the suspension was heated to boiling for 5 minutes and stirred to extract all the chloride ions in grout and IER. The suspension was filtered to remove the powder of grout and IERs. The amount of chloride ions in the solution was quantitatively analyzed using potentiometric titration against silver nitrate.

\section{PROPERTIES OF GROUT: STRENGTH, BLEEDING AND FLOWABILITY}

\section{Materials and mix proportions}

Same type of IER, grinded in powder and sieved through $300 \mu \mathrm{m}$ mesh, was used in this experiment. Herein, to make the grout, a commercial product of cementitious non-shrink grout powder from Taiheiyo Material Corp., named Premix-AD, was mixed with water and IERs. Premix-AD is a premixed grout material without expansion. It has a low viscosity and good property against bleeding, so is widely used to make normal grout. Table 4 shows the water to the grout powder $(w / p)$ ratio and the addition ratio of IERs by volume in the mix proportions in this test. 
Table 4. Mix proportions for strength, bleeding and flowability tests

\begin{tabular}{|c|c|}
\hline IER addition rate by volume of grout $(\%)$ & W/P $(\%)$ \\
\hline $3,4,5$ & $41,43,45$ \\
\hline 7 & 43,45 \\
\hline 8 & 45 \\
\hline
\end{tabular}

\section{Test methods and acceptance criteria to evaluate the performance of the grout}

Table.5 shows the test methods in the standard of Japan Society of Civil Engineers (JSCE), for the properties of bleeding, flowability and compressive strength, respectively. All the tests in this paper followed those method. In the compressive strength test, cylindrical specimens with $100 \mathrm{~mm}$ height and $50 \mathrm{~mm}$ diameter were prepared, and cured with sealing at $20{ }^{\circ} \mathrm{C}$ until the ages of test. They were 7 days and 28 days, respectively. Bleeding ratio was tested according to "Test method for bleeding ratio and expansion ratio of grout for prestressing tendons (polyethylene bag method)". Cylindrical polyethylene bag with $50 \mathrm{~mm}$ diameter and $500 \mathrm{~mm}$ length was prepared Grout was filled in the bag to the height of $200 \mathrm{~mm}$, and air bubbles were carefully avoided. The bag was immersed in a graduated cylinder filled with $400 \mathrm{~mL}$ water, to measure the volume of grout. After that, the bag was hanged for 3 hours. The bleeding water was soaked using a pipette, and its volume was measured. The volume of bleeding water was measured again at the time of 20 hours. Dividing the volume of bleeding water by that of the grout, bleeding ratio was calculated. In the flowability test, a flow cone which had a height of $392 \mathrm{~mm}$, a top diameter of $70 \mathrm{~mm}$, and an efflux opening at the bottom with $14 \mathrm{~mm}$ diameter, was prepared. The internal wall of the cone was preliminarily wetted with water. Blocking the efflux opening, the cone was fully filled to the top with the grout. Then, the efflux opening was opened to drop the grout flow. The time until the cross section of the flow suddenly became thin was recorded as the flow time. Since the flowability is closely influenced by the elapsed time from mixing, the flow test was conducted 0,30 and 60 minutes after mixing of the grout, respectively. All the tests were conduct at a constant temperature of $20{ }^{\circ} \mathrm{C}$.

Table 6 shows the acceptance criteria for those properties defined in the code of Japan Prestressed Concrete Engineering Society. Grout for practical use should satisfy those criteria. The bleeding ratio should be below $0.3 \%$. The flow time in the cone test should below 14 seconds. Compressive strength should be above $30 \mathrm{MPa}$ and $40 \mathrm{MPa}$ at 7 day and 28 day, respectively.

Table 5. Properties and test methods

\begin{tabular}{|l|l|}
\hline Properties & \multicolumn{1}{c|}{ Test method } \\
\hline Bleeding & $\begin{array}{l}\text { Test method for bleeding ratio and expansion ratio of grout for prestressing } \\
\text { tendons (polyethylene bag method) (JSCE-F532-2013) }\end{array}$ \\
\hline Flowability & Test method for flowability of grout for prestressing tendons (JSCE-F531-2013) \\
\hline Compressive strength & $\begin{array}{l}\text { Test method for compressive strength of grout for prestressing tendons } \\
\text { (JSCE-G531-2012) }\end{array}$ \\
\hline
\end{tabular}

Table 6. The acceptance criteria for the properties of PC grout

\begin{tabular}{|l|l|}
\hline Properties & \multicolumn{1}{|c|}{ Criteria for the properties } \\
\hline Bleeding & $\leqq 0.3 \% \quad \leqq 14$ seconds (for low viscosity type) \\
\hline Flowability & $\geqq 30 \mathrm{MPa}$ at 7 day $\quad / \quad \geqq 40 \mathrm{MPa}$ at 28 day \\
\hline Compressive strength & $\geqq$ \\
\hline
\end{tabular}




\section{EXPERIMENTAL RESULT}

\section{Chloride absorption}

The analysis results of chloride amount exisiting in grout are shown figure 4. This amount includes not only free chloride ions in pore solution of the grout, but also those chloride fixed by the grout and exchanged by the IER. For the case of B1, only the results of 56 days were analyzed, but it is obvious that as the addtion ratio of IER increased, more chloride were detected in the grout. For the other cases of B2, $\mathrm{C} 1$ and $\mathrm{C} 2$, although not so obvous as that of $\mathrm{B} 1$, the trend of increase of chloride amount can be still observed if more IERs were mixed in the grout. For those grouts without IER addtion (i.e. 0\%), some amount of chloride could also be detected in the grout. This is because the diffusion of chloride ions from the surface of tendon to the grout. Dispite that, undoutably, with the existence of IERs, this diffusion was accelerated due to the exchange of chloride ions. In addtion, if comparing the results of 28 days and 56 days, it can found that the absorption effect was more obivous at early age. According to those results, it can be inferred that, in the vicinity of the surface of the tendon, the amount of chloride decreased more if the IER mixed grout was used. Therefore, from the results, it is confirmed that IER mixed grout has the potential to be used as the regrouting material with the capacity of removing chloride near tendon. In the future study, the corrosion process of tendon needs to be investigated experimentally, in order to clearly know the effect of allevation of corrosion.

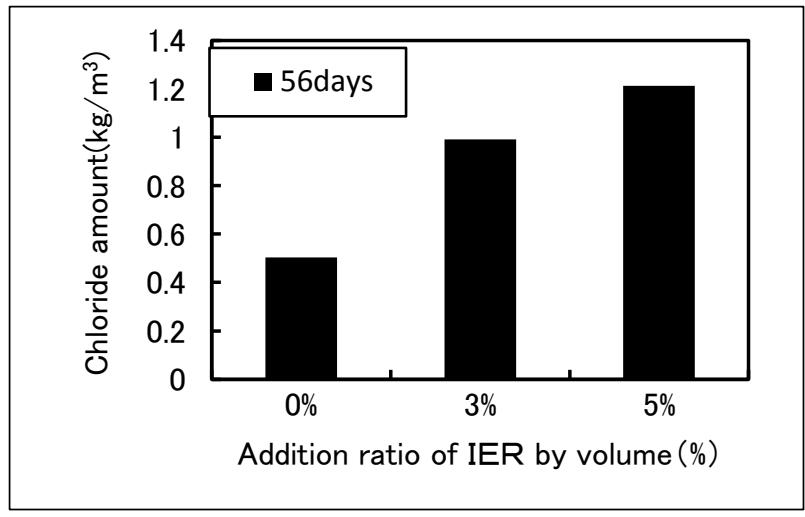

(a) B1

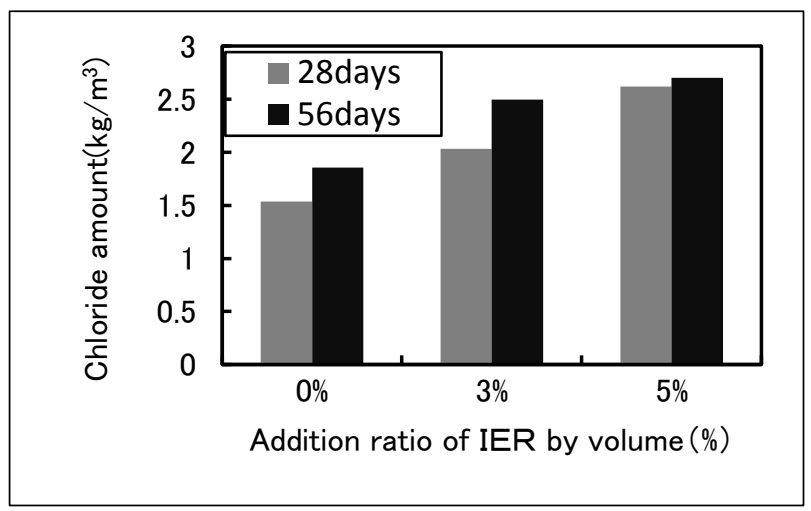

(c) $\mathrm{C} 1$

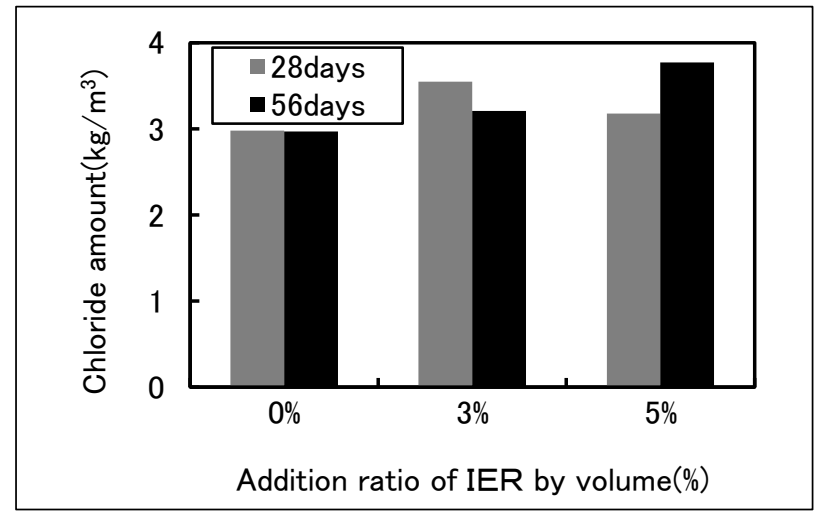

(b) B2

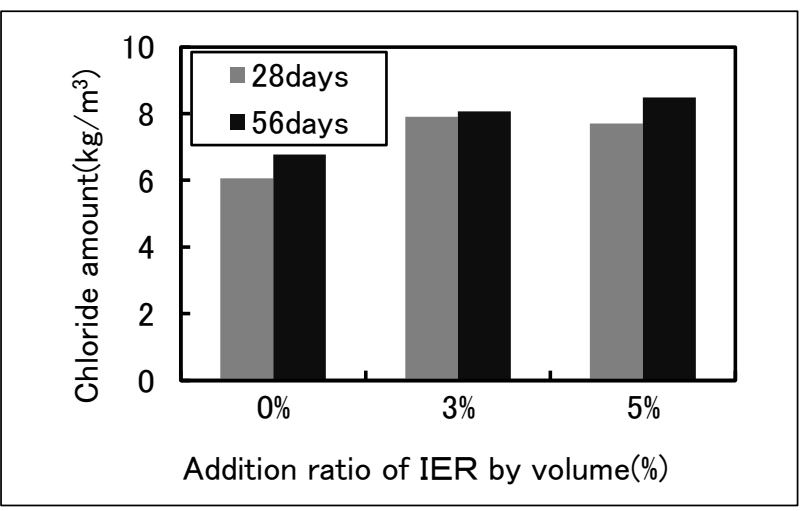

(d) $\mathrm{C2}$

Figure 4. The analysis result of chloride absorption for different chloride spreading 


\section{Compressive strength}

Figure 5 shows the test results of the compressive strength. It can be found that, for the replacement ratios of 3\%, $4 \%$ and 5\% with IER, the compressive strengths of 7 day were all higher than $30 \mathrm{MPa}$, while those of 28 day were all higher than $40 \mathrm{MPa}$. Although strength decreased as w/p increased, the replacement ratios of 3\% 5\% satisfied the requirements in the acceptance criteria. On the other hand, for higher replacement ratios of IER such as $8 \%$, the strength at 28 days was slightly lower than $40 \mathrm{MPa}$, so did not satisfy the requirement. In general, compressive strength decreased as the replacement ratio of IER increased, because IER itself did not hydrate but only absorbed water.

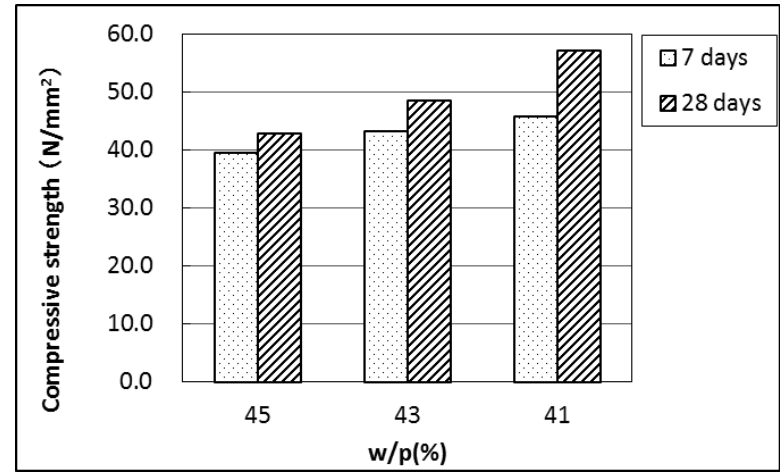

(a) addtion ratio of IER $3 \%$

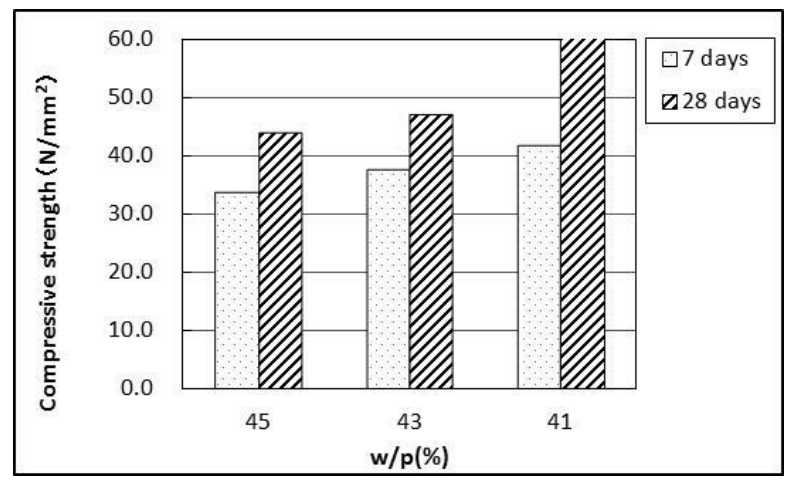

(c) addtion ratio of IER $5 \%$

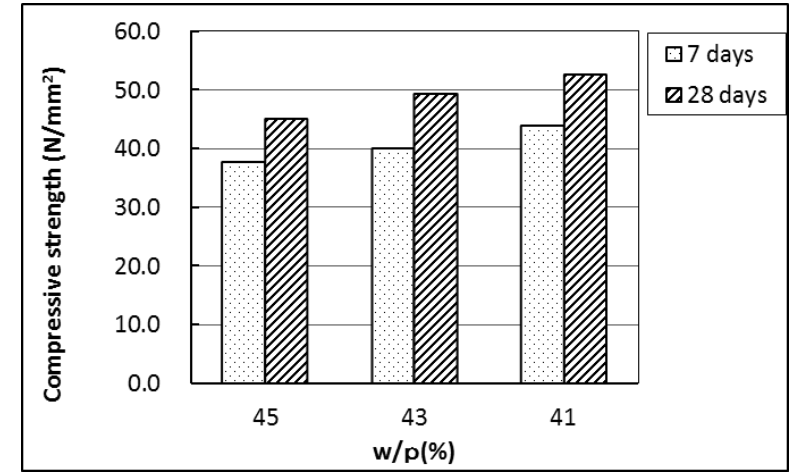

(b)addition ratio of IER 4\%

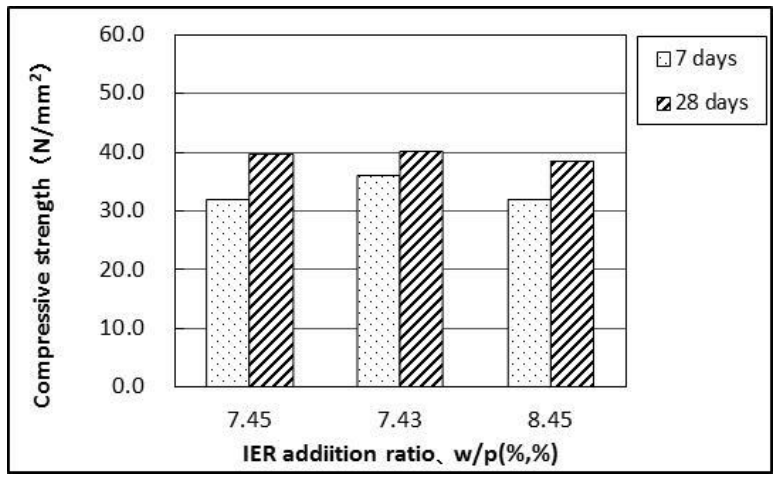

(d) addtion ratios of IER $7 \%$ and $8 \%$

Figure 5. The test results of compressive strength

\section{Bleeding ratio}

The test results of bleeding ratio are shown in Table 7. In all the cases, the bleeding ratios of the grout, both 3 hours and 24 hours after the mixing, were zero. Herein, the premixed type grout showed excellent property against bleeding, in spite of the addition of IER.

Table 7. The test results of bleeding ratio

\begin{tabular}{|c|c|c|c|}
\hline $\begin{array}{c}\text { IER Addition ratio } \\
(\%)\end{array}$ & $\begin{array}{c}\text { W/P } \\
(\%)\end{array}$ & $\begin{array}{c}\text { Bleeding ratio 3 hours after } \\
\text { mixing }(\%)\end{array}$ & $\begin{array}{c}\text { Bleeding ratio 24 hours after } \\
\text { mixing }(\%)\end{array}$ \\
\hline 3 & $41,43,45$ & 0 & 0 \\
\hline 4 & $41,43,45$ & 0 & 0 \\
\hline 5 & $41,43,45$ & 0 & 0 \\
\hline 7 & 43,45 & 0 & 0 \\
\hline 8 & 45 & 0 & 0 \\
\hline
\end{tabular}




\section{Flowability}

The test results of the flowability are shown in Figure 6 and Figure 7. In each addition ratio of IER, the flow time in the cone over an elapsed time after mixing, which were 0,30 and 60 minutes, respectively, are compared. As the acceptance criteria, time should be less than or equal to 14 seconds. From the results, generally the flow time increased more or less as the elapsed time increased. It can be found that, for the case of addition ratio $3 \%$ and $\mathrm{w} / \mathrm{p} 45 \%$, even if an elapsed time of 60 minutes, it still satisfied the acceptance criteria. For the cases of addition ratios $4 \%$ and $5 \%$, when the w/p was $45 \%$, after an elapsed time of 30 minutes, they still satisfied the criteria. After 60 minutes, their flow times increased a lot, so did not satisfy the criteria any longer. For other mix proportions, after the elapsed time of 30 minutes, the flow time increased significantly, so could not satisfy the criteria. In general, as IER addition ratio increased or w/p decreased, the flowability decreased. Due to its porous structure, IER can easily absorb water from the paste, so decreased the flowability.

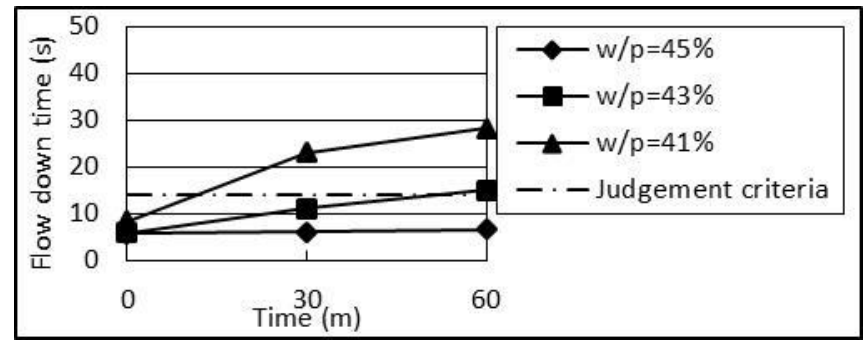

(a) IER addition ratio $3 \%$

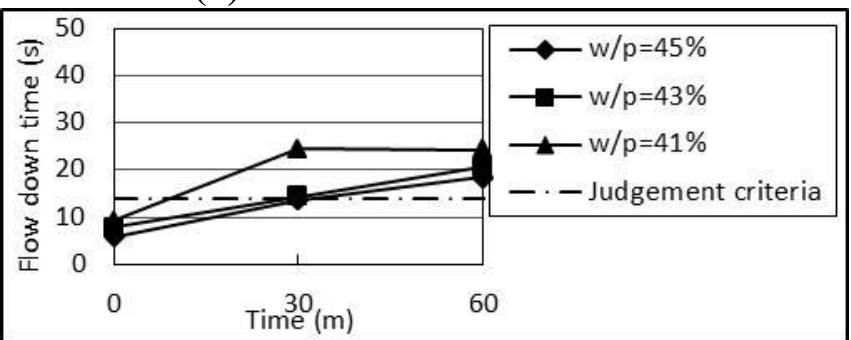

(b) IER addition ratio $4 \%$

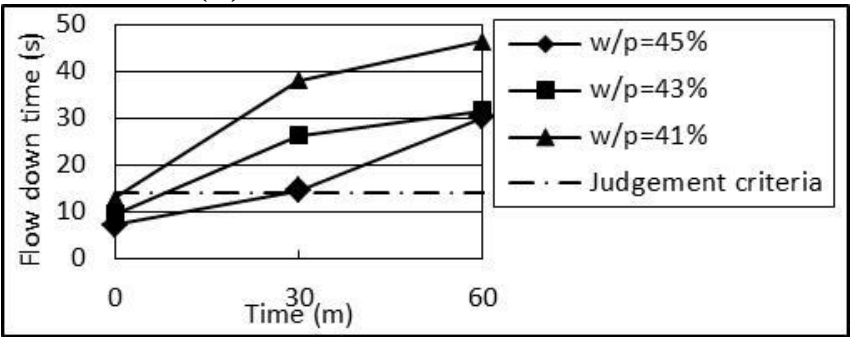

(c) IER addition ratio $5 \%$

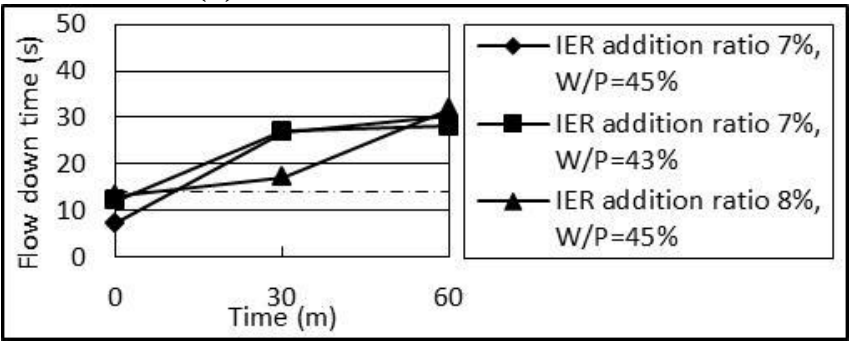

(d) IER addition ratios $7 \%$ and $8 \%$

Figure 6. Flow time of grout for different w/p ratios 


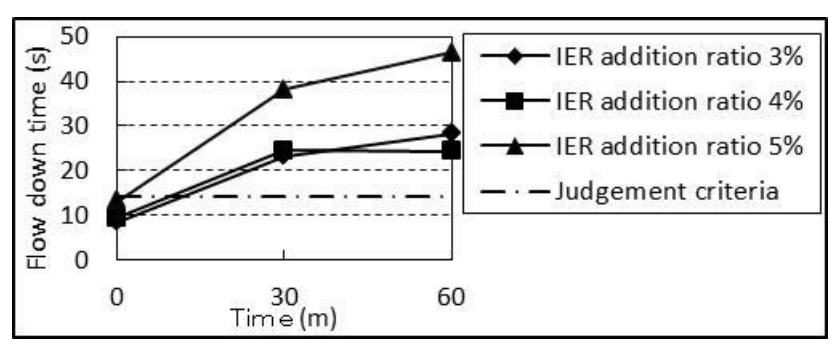

(a) $\mathrm{W} / \mathrm{P}=\mathbf{4 1 \%}$

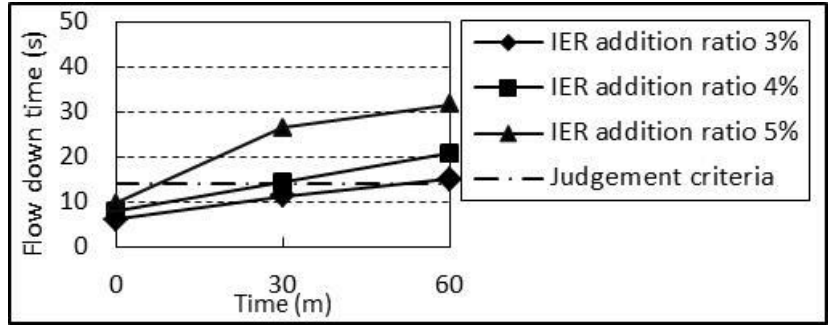

(b) $\mathrm{W} / \mathrm{P}=43 \%$

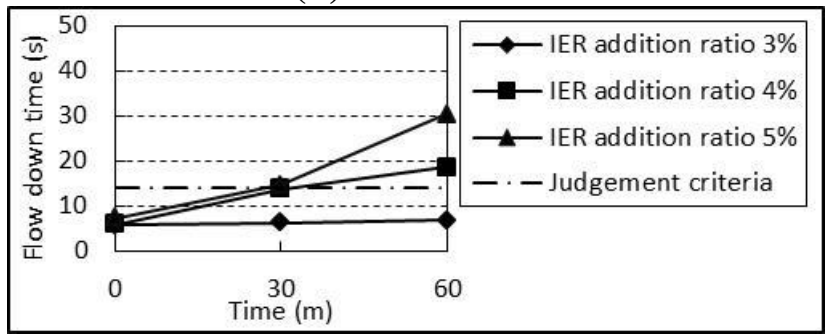

(c) $\mathrm{W} / \mathrm{P}=\mathbf{4 5 \%}$

Figure 7. Flow time of grout for different IER addition ratios

Mix proportion with optimal properties of compressive strength, flowability and bleeding ratio. A mix proportion with the potential of practical use should satisfy all the acceptance criterias in Table 6 . Table 7 already shows that all the mix proportions had good performance against bleeding. Herein only the 28 day compressive strength and flow time are summarized in Figure 8. The upper-right area indicates the range that flow time is less than 7 seconds and the compressive strength is above $40 \mathrm{MPa}$. It can be found that three mix proportions, which are IER ratio 3\% with w/p 45\%, IER ratio 3\% with $\mathrm{w} / \mathrm{p} 43 \%$, IER ratio $4 \%$ with $\mathrm{w} / \mathrm{p} 45 \%$, are in this area. Those grouts had even better flowability than that in the acceptance criteria. They could be regarded as the type of super-low-viscosity.

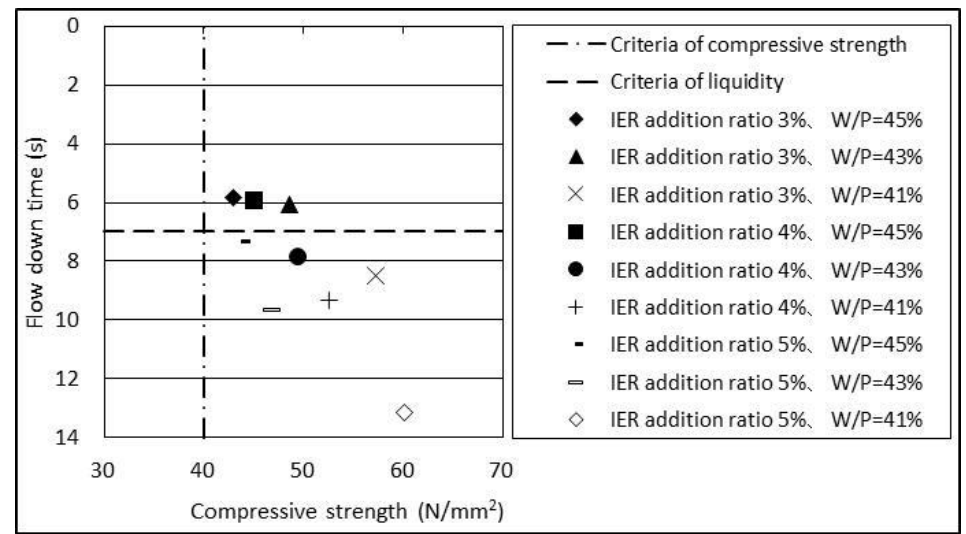

Figure 8. Relationship between the compressive strength and flow time 


\section{CONCLUSION}

In this study, the authors mixed ion-exchange resin in grout, and investigated its capacity of absorbing chloride ions from the surface of tendon. Sodium Chloride solution or solid particles were preliminarily spread and smeared at the surface of the imitated tendon. The ducts containing the tendon were grouted using IER mixed grout with different addition ratios. After curing for 28 days and 56 days, the grout was grinded into powder, and sampled to analyze the chloride content quantitatively. It was found that for the grout with higher addition ratio of IER, the higher amount of chloride ions could be found in the grout. This implies that IER mixed grout can absorb chloride ions from the surface of tendon, so has the potential of alleviating the corrosion. Furthermore, for practical use, grout must satisfy the acceptance criteria of strength, bleeding and flowability. Using a premixed grout powder to make the grout, different ratios of IER were added. The strength, bleeding ratio and flow time of the IER mixed grout were tested according to the methods of JSCE. It is found that as IER ratio increased, strength and flowability tended to decrease but bleeding did not occur. However, when mix proportion and addition ratio of IER were adopted properly, those properties satisfied the acceptance criterias in the standard. In the future, the corrosion process of tendon which are regrouted using the IER mixed grout will be investigated experimentally, to further study its effect for the repair.

\section{ACKNOWLEDGEMENTS}

The authors would like to sincerely express the appreciation to Mr. Yamanaka and Ms. Ito from Organo Corporation for the help of analysis.

\section{REFERENCES}

JPCI. "Design and Construction Guidelines of PC grout -Revised Edition-", Japan Prestressed Concrete Institute, II -63-67, 5 pages.

Osamu, S., Hiroshi, M., and Yao, L. (2014).'Experimental study on Chloride Diffusion of Grout Mixed Ion-Exchange Resin ”, 23th symposium on Development of Prestressed Concrete, 71-76.

Osamu, S., Hiroshi, M., and Atsushi, S. (2014). "Effect of Chloride Ion Diffusion in Mortar Mixed with Ion-Exchange Resin", $2^{\text {nd }}$ International Congress on Durability of Concrete, 22, Paper Number 6.

Yao, L., Hiroshi, M., and Osamu, S. (2015). "A Study on The Performance with A Grout that were Mixed Ion-Exchange Resin”, 70th JSCE Annual Scientific Lectuer Abstract Collection, 909-910. 